\title{
Fluid-filled striae in a patient with hypoalbuminemia
}

\author{
Maria Jogova MD, Stephen W. Hwang MD MPH
}

Cite as: CMAJ 2017 July 17;189:E942. doi: 10.1503/cmaj.161410

A 57-year-old woman presented with progressive severe edema that affected her limbs and trunk and a one-week history of nonbloody diarrhea. On examination, she also had numerous linear, lobulated, fluid-filled skin lesions (Figure 1) that flattened with transient pressure. These were a result of fluid gathering within pre-existing stretch marks. Investigations were consistent with hypoalbuminemia (serum albumin $<15$ [normal 35-50] g/L; urine protein 0.12 g per 24 hours), secondary to protein-losing enteropathy associated with Clostridium difficile infection. Liver enzymes were normal. The lesions resolved following treatment with antibiotics and diuresis.

Striae distensae, also known as stretch marks, are a form of dermal scarring that present initially as reddish-purple linear plaques (striae rubrae) before fading into hypopigmented, atrophic lesions (striae albae). ${ }^{1}$ Striae distensae are associated with pregnancy, rapid weight gain, and systemic or topical corticosteroid use; they most frequently develop in women and teenagers. ${ }^{1,2}$ In conditions characterized by severe edema, such as various causes of hypoalbuminemia and heart failure, interstitial fluid can collect preferentially within pre-existing striae distensae, where the tissue's tensile strength is reduced because of an atrophic epidermis overlying areas of abnormal dermal collagen. ${ }^{2,3}$ Bullous autoimmune skin conditions and bullous infections must also be considered in the differential diagnosis. ${ }^{3}$ Diuresis results in flattening of the fluid-filled lesions. ${ }^{2}$ Awareness of this striking but benign skin finding in patients with hypoalbuminemia can prevent unnecessary interventions.

\section{References}

1. Al-Himdani S, Ud-Din S, Gilmore S, et al. Striae distensae: a comprehensive review and evidence-based evaluation of prophylaxis and treatment. $\mathrm{Br} J$ Dermatol 2014;170:527-47.

2. Lee JH, Lee EK, Kim CW, et al. A case of edematous striae distensae in lupus nephritis. J Dermatol 1999;26:122-4.

3. Seshadri D, De D, Rathi M, et al. Fluid within striae - an unusual phenomenon. $J$ Case Rep 2013;3:331-3.

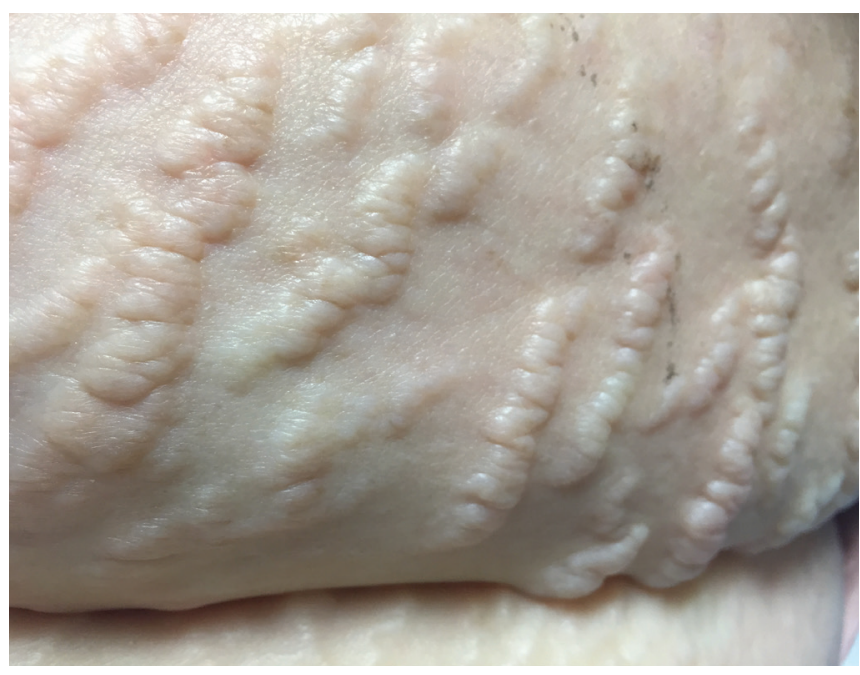

Figure 1: Fluid-filled striae distensae on the lateral abdomen of a 57-yearold woman with severe edema secondary to hypoalbuminemia.

\section{Competing interests: None declared.}

This article has been peer reviewed.

The authors have obtained patient consent.

Affiliations: Department of Medicine (Jogova, Hwang), University of Toronto; Centre for Urban Health Solutions (Hwang), St. Michael's Hospital, Toronto, Ont.

Correspondence to: Maria jogova, mariajogova@gmail.com

Clinical images are chosen because they are particularly intriguing, classic or dramatic. Submissions of clear, appropriately labelled high-resolution images must be accompanied by a figure caption. A brief explanation (300 words maximum) of the educational importance of the images with minimal references is required. The patient's written consent for publication must be obtained before submission. 